\title{
Local clusters in global value chains: exploring dynamic linkages between Germany and Pakistan
}

\author{
KHALID NADVI $\uparrow$ and GERHARD HALDER $\$$ \\ $\dagger$ Institute of Development Policy and Management (IDPM), School of \\ Environment and Development, University of Manchester, Harold Hankins \\ Building, Oxford Road, Manchester M13 9QH, UK; \\ e-mail: khalid.nadvi@manchester.ac.uk \\ \#Institute of Geography, University of Stuttgart, Azenbergstrasse 12, Stuttgart \\ 70174, Germany; e-mail: ghalder@geographie.uni-stuttgart.de
}

\begin{abstract}
Recent research has underlined the importance of external linkages for industrial clusters. Suppliers and buyers within a global value chain offer important external ties for clusterbased producers not only in terms of the distribution of physical goods, but also for knowledge flows and innovation. Globalization has intensified such value chain links, connecting geographically dispersed producers to global markets. Yet, there is limited research on how local clusters enter global chains or on ties between clusters in the developed and developing world. This study addresses this gap. It uses the case of the global surgical instrument industry to analyse connections and differences between the industry's leading production clusters in Germany and Pakistan. Global standards, low-cost competition, and advances in medical technology raise challenges for both clusters. The paper explores the responses to these challenges. It distinguishes between knowledge and production links to illustrate differentiation in each cluster, diverging trajectories and continuing ties.
\end{abstract}

Keywords: industrial clusters; global value chains; networks; innovation; developing countries.

\section{Introduction}

Since the 1990s, many studies have shown that competitiveness can be enhanced in geographically concentrated and sector-specialized industrial clusters or districts (Brusco 1990, Krugman 1991, Schmitz 1995, Markusen 1996, Scott 1996, Porter 1998, Gordon and McCann 2000). The allure of the cluster approach lies in its promise for small-scale industry and the importance it attaches to local linkages. It shows that, with economies of agglomeration and local joint action, small and medium sized enterprises (SMEs) can compete alongside large firms and in global markets. Cluster-specific external economies include the presence of skilled labour, specialist suppliers, and knowledge spillovers. Economies of scale and scope emerge when firms concentrate on particular processes and produce complex goods by interacting with each other. High levels of organizational flexibility within small firms lead to further cost advantages. Finally, local joint action, between firms and through local institutions can enhance the capacity of small firms and raise a cluster's competitiveness. 
Evidence of globally competitive clusters is found in both the developed and developing world (see, for example, Best 1990, Garofoli 1992, Pyke and Sengenberger 1992, Nadvi and Schmitz 1999, and van Dijk and Sverrisson 2003). Yet, despite these gains, we now know that clusters are neither homogenous (Harrison 1994), nor that they follow a 'natural' and sustained growth path (Belussi 1999, Whitford 2001). Moreover, there is growing evidence that alongside internal linkages, external ties with suppliers and customers located outside the cluster also matter (Garofoli 1994, Harrison 1994, Rabellotti 2004). Globalization has strengthened the view that the success of many clusters, especially in the developing world, is closely tied to external actors who connect such clusters to global markets (Schmitz and Nadvi 1999). The global value chain approach, which maps the complex links between globally dispersed producers and global buyers, has underlined the importance of global buyers and lead firms in co-ordinating the organization of global production and distribution (Gereffi 1994). This has sparked interest amongst cluster analysts in examining ties between local clustered firms and global buyers (Schmitz and Knorringa 2000), and between local clusters and global chains (Humphrey and Schmitz 2002).

What is often overlooked, however, are global value chain ties with producers, suppliers and buyers located in other clusters and engaged in similar activities. This aspect of external linkages can reflect differences in knowledge and productive capacities between interlinked clusters. This is especially so where one of the clusters is located in a low-waged developing country and the other in the knowledge and capital rich developed world. Empirical work on such interlinked clusters could offer important insights into cluster dynamics as well as the global relations of clustered firms within a value chain. This raises three questions for us. First, how are clusters from the developed world connected through global value chains with clusters in the developing world? Second, how do such clusters respond to similar global challenges? Third, how is local upgrading influenced by production and knowledge ties within the global chain and the local cluster?

Observing that local clusters have global connections is not new. Amin and Thrift (1992) have long argued that clusters are 'nodes' within global networks. However, studies on inter-cluster ties are rare (exceptions include Scott 1994, Rabellotti 1997, Meyer-Stamer et al. 2004). Moreover, understanding the role of such external links on processes of local upgrading within clusters is especially weak. We focus on these gaps. The global surgical instruments industry provides us with an exemplary case study in that two quite distinct but closely related clusters, one in Sialkot, Pakistan and the other in Tuttlingen, Germany play a major role in the industry. In terms of innovation and quality the two clusters mark the lower and higher ends of the global industry, but, in terms of production, they are closely linked.

Using primary and secondary evidence from both clusters we study how the two clusters work as specific, but inter-connected, nodes. ${ }^{1}$ In order to obtain a dynamic perspective on these nodes, we distinguish between the analysis of production systems, which encompass the production of goods to desired specifications, and that of knowledge systems, that generate and manage changes in the production process or the organization of production (Bell and Albu 1999). This distinction between knowledge flows and production flows provides an important organizing principle to the paper and is central in explaining the nature of linkages between the two clusters and their dynamic responses to the common global challenges that they currently face. These challenges include meeting higher global quality standards, facing greater low-cost 
competition, and reacting to new developments in health care delivery and medical technology. We study the responses of the two clusters to these challenges, and the implications for the relationships between them as well as for their growth dynamics. The next section considers the importance of external knowledge flows, especially through global value chains, to cluster upgrading. Section 3 provides an overview of the global surgical instruments sector, outlining the two clusters and their main connections. Section 4 reports on upgrading responses in each cluster in the face of common challenges. Section 5 focuses on the material and knowledge flows across the two clusters that influence such upgrading. The paper concludes by considering the future trajectories for Tuttlingen and Sialkot.

\section{Clusters, value chains and upgrading}

Much of the recent conceptual discussion on clusters has focused on the process of knowledge generation and dissemination (Bathelt et al. 2004). Malmberg and Maskell (2002: 442) argue that at the horizontal and vertical dimensions of cluster relationships, distinct mechanisms work to enhance learning dynamics. Thus, strong inter-firm rivalry at the horizontal level alongside more trust-based relations at the vertical level can work together to promote learning. This may be further facilitated through an institutional dimension of a cluster. It is widely acknowledged that a strength of clusters reside in the rapid use, replication and circulation of knowledge within the cluster's boundaries (Nadvi 1999a). Technological similarities of firms and social coherence of personal actors can promote such patterns of learning (Bathelt et al. 2004). However, the circulation, absorption and modification of already existing knowledge within the cluster rarely alter the stock of knowledge in more than an incremental way (Humphrey and Schmitz 2000). In fact, a concentration on internal mechanisms and a 'regional gaze' that fails to look beyond the boundaries of the cluster are elements of recent critiques of previous work on industrial clustering (Lagendijk 2002).

Radical upgrading, be it technological, processual or functional in nature, often requires a combination of external and internal knowledge (Bell and Albu 1999, Bathelt et al. 2004). It is argued, that even world-class clusters need external ideas and inspiration to retain their dynamism, and cannot rely on their own expertise to bring about sustained technological developments. Thus, the long-term success of a cluster is tied to the ability of clustered firms to build channels to external partners providing complementary and new knowledge.

This emphasis on external and internal linkages in understanding cluster dynamics requires a conceptual framework to analyse local and global ties. The value chain approach provides a useful model (Gereffi 1994). It shows how the distinct functions involved in turning a raw material into a final product can be mapped onto the complex inter-relations that exist between local suppliers and their global buyers. The approach emphasizes the role of governance, or conscious co-ordination, of distinct activities within the chain. This highlights the significance of power in the chain (Gereffi et al. 2002, Bathelt and Taylor 2004). The influence of actors in the chain can vary, affecting their ability to determine the parameters of production including what is produced, how, when, and at what price (Humphrey and Schmitz 2002). Co-ordinating inter-firm relationships can involve network arrangements between relatively equal partners who share complementary skills and abilities; 
quasi-hierarchical ties in which one actor has disproportionately more power over other independent actors; or hierarchical vertical integration (Humphrey and Schmitz 2002). These distinct forms of chain governance explain how a chain is structured, and where and how value is added and appropriated. Chain governance also impact on the scope for local actors to promote upgrading and growth.

There have been a few attempts to analyse local clusters using a value chain framework. Knorringa's (1996) research on the Agra footwear cluster in India indicated that the cluster's structure was best understood by reviewing the ways in which local producers were inserted into distinct types of local and global value chains. Schmitz's (1999) study, and the subsequent work by Bazan and NavasAleman (2004), on the Brazilian footwear cluster of Sinos Valley, suggested that global chain ties could supersede local cluster initiatives, and cause further differentiation within the cluster. Rabellotti's (2004) research on the Brenta footwear cluster in Italy went further, showing how upgrading is directly conditioned by chain governance. Production for luxury designer brands resulted in higher value added in Brenta but required a 'de-skilling' in functional activities previously undertaken by the cluster. The move away from retailing and design was a direct outcome of chain governance. In contrast, Bair and Gereffi's (2001) study of the Mexican denim jeans cluster in Torrean pointed to a complex pattern of local upgrading linked to chain governance. Upgrading was a consequence of trade regimes (NAFTA) and the links that Torrean's garment manufacturers had with producers, retailers and brand marketers from the USA.

These studies highlight the significance of external links to cluster dynamics. They point to the differing ways in which global chain ties can effect local cluster upgrading. However, they do not address the role of inter-cluster ties, nor how production and knowledge flows between clusters influence cluster dynamics.

\section{The global surgical instruments industry and local clusters}

Historically, hand-held steel surgical instruments were manufactured in regions known for traditional artisanal metalworking. The distinct production tasks promoted a division of labour whereby small firms flourished and local clusters emerged. Thus, in the early twentieth century, clusters of surgical instrument production were found in Sheffield (UK), Nogent-sur-Marne (France), and Solingen and Tuttlingen (Germany). With the exception of Tuttlingen, none of these locations survive as significant centres for surgical instrument manufacture today. Instead, the last quarter of the twentieth century has seen a number of new actors, such as Pakistan, Malaysia, Poland and Hungary, emerge as important producers of traditional surgical instruments.

\subsection{The global industry}

The scale of the global surgical instruments industry is difficult to measure as trade data is unavailable at the required level of disaggregation. Thus, while world exports of medical instruments and appliances (SITC code 872) were US $\$ 100$ billion in 2004, and the sub-category of 'other surgical, veterinary and medical instruments' (SITC 87229) was US\$ 40 billion (United Nations 2005), hand-held surgical instruments 
accounted for only a small sub-sector within this. Our own estimates, drawn from key informants, suggest a global industry of over US\$ 1 billion. Within this Tuttlingen, with a total annual turnover estimated to be US\$ 610 million in $1999,{ }^{2}$ is reported to have a $55 \%$ share of the global market (in traditional and new instruments), while Pakistan, with exports of over US\$ 126 million in 2003 (United Nations 2005), is said to account for one-fifth of the global market of traditional surgical instruments. In contrast, exports of surgical instruments in 2003 from Malaysia, Poland and Hungary were US\$ 45 million, US\$ 52 million, and US\$ 42 million, respectively (United Nations 2005).

There are key similarities and differences between Tuttlingen and the emergent producers. In each country, production is concentrated in specific locations: Sialkot (Pakistan), Penang (Malaysia), Debrecen (Hungary) and Novy Tomsyl (Poland). Both Sialkot and Tuttlingen have a similar background in metalworking. However, while Tuttlingen and Sialkot have over 300 surgical instrument manufacturers each, there are only a few firms in Penang, Debrecen and Novy Tomsyl. There are also differences in the types of instruments produced. Sialkot, Penang, Debrecen and Novy Tomysl primarily manufacture traditional, stainless steel hand-held instruments. These include cheaper and lower quality 'floor' or disposable instruments and higher quality 'theatre' or operation instruments. Tuttlingen manufactures theatre instruments but has also diversified into a wide range of new, higher value-added products including minimal invasive instruments, endoscopes, surgical appliances and surgical implants. Furthermore, Tuttlingen is the only production site with direct ties to all the other production centres. Malaysian production is dominated by the wholly owned subsidiary of Tuttlingen's largest manufacturer. Plants in Poland are either owned by, or closely tied to, Tuttlingen firms. In Hungary, there is only one large producer that sells primarily through its own Tuttlingen-based trading firm. A number of firms in Pakistan undertake job processing and original equipment manufacture (OEM) production of floor and theatre instruments for Tuttlingenbased firms and traders.

The leading global markets for surgical instruments are the USA, the European Union and Japan. Not all the production centres trade directly in these markets. Polish and Hungarian production is channelled through producers and traders in Tuttlingen. Malaysian exports were originally 'routed' through Tuttlingen, but are increasingly exported directly, especially to Japan. Most striking is Pakistan. While a significant component of its exports of surgical instruments is traded with Tuttlingen, the vast bulk goes directly to buyers in the US and EU markets. These trade and production linkages underline the global nature of the industry, and the role of Tuttlingen as one organizing hub. They also point to the ways in which Tuttlingen and Sialkot are key pillars of the industry. We examine these two clusters more closely.

\subsection{Sialkot ${ }^{3}$}

Surgical instrument manufacture constitutes a small export-oriented industry in Pakistan, located solely in and around the city of Sialkot and employing over 30000 workers (Nadvi 1999a). At its core are some 350, mainly small, family-run, manufacturing and exporting firms. About 30 large firms, employing 100 or more persons, are at the forefront of the industry. In addition, there are various local input 
suppliers, service providers, over 1500 specialist sub-contractors and a number of local public and private support institutions.

Sialkot produces a variety of standard instruments, relying heavily on labour intensive techniques. Its strength is in lower quality, relatively cheap and high volume disposable instruments, but it also produces higher quality theatre instruments. Export volumes have risen systematically, from US\$ 76 million in 1990 to US\$ 141 million in 2002 (United Nations 2005). In 1990 over 85\% of exports were to the USA and the EU, although by 2002 this had fallen to $71 \%$ of total exports (United Nations 2005). The USA accounts for the bulk of disposable exports while theatre instruments are mainly destined for the EU. There are four distinct distribution channels through which local firms export. These include:

- foreign buyers (including Tuttlingen traders) who purchase complete instruments from Sialkot and supply wholesalers, retailers and end-users in specific markets;

- Tuttlingen producers who sub-contract all or part of particular instruments to Sialkot, or use Sialkoti firms as OEM suppliers;

- expatriate Pakistani traders who supply (usually lower quality) instruments in various markets, especially in the USA; and

- foreign sales outlets (or subsidiaries) of Sialkot manufacturers.

The continued export success of local firms is tied to the externality gains of clustering. Extensive and well-developed local markets for inputs, services, and skilled labour ensure easy availability and competitive prices. The flow of sector-specific and technical information within the cluster generates important knowledge spillover gains for local firms. Widespread subcontracting provides economies of scope and scale, with savings on costs, skills and space.

Despite intense local competition, local joint action raises the cluster's competitiveness. Bilateral co-operation between local producers is rare. Nevertheless, co-operation through local institutions has been critical at key moments in the cluster's history. For example, constraints in handling exports in Pakistan's main port in the 1980s led to an initiative by the Sialkot's leading firms to develop a local 'dry' port that brought customs handling to the cluster's doorstep (Nadvi 1999a). Similarly, the sector's trade association successfully organized a cluster-wide response to pressures by US regulators in the mid-1990s to comply with global quality assurance standards (Nadvi 1999b). Joint action is also present in vertical ties. Firms have long-standing relations with subcontractors, involving technical discussion on quality and production organization. Ties with buyers are especially significant. Firms often receive support from buyers in improving product quality and buyers are cited as the primary source for new ideas on product development. Such technical support is pronounced where firms deal with buyers who are also instrument producers, particularly from Tuttlingen.

\subsection{Tuttlingen ${ }^{4}$}

The small town of Tuttlingen, and its surrounding rural hinterland, is home to about $75 \%$ of Germany's surgical instrument industry. Some 300 producers of final instruments, approximately 180 subcontractors and 200 home-workers together employ 6200 persons in the cluster. There are a further 76 specialist traders, with 
over 600 employees in 1999. The cluster benefits from an array of input and machine tools suppliers in Tuttlingen and nearby towns and villages. The size distribution of manufacturing firms is more uneven than in Sialkot. Eight firms account for $64 \%$ of total manufacturing employment in the sector, with more than 200 owner-operated 'one-person' firms at the other end of the scale. The cluster's largest firm employs some 2000 persons in Tuttlingen, accounting for $32 \%$ of Tuttlingen's total manufacturing workforce.

The cluster is differentiated by two distinct product sub-sectors: traditional surgical instruments and new products such as endoscopes, surgical apparatus and surgical implants. In terms of employment, surgical instruments production is the main activity with $30.5 \%$ of total manufacturing employment within Tuttlingen's medical technologies sector. However, while the cluster's largest producer (Aesculap) produces instruments, implants and other surgical products, the remaining nine of the ten largest firms in Tuttlingen specialize in the new product sector. In contrast, small firms employing less than 20 persons predominantly work in the instruments sub-sector.

In 1999, the cluster exported roughly two-thirds of its total output, mainly to the USA, the European Union and Japan. The wide range of instruments produced locally, along with small (and often irregular) batch sizes, promotes high quality craft production. It also implies that traders and producers need to maintain a large and diversified stock to meet changing demands. Production processes for standard instrument manufacture are similar to those in Sialkot, although specialist process technology is more commonly used. Manufacture of surgical implants and endoscopes is technically more complex and less labour-intensive. Process subcontracting does take place, but only in instrument production and the practice is not as extensive as in Sialkot. Instead, many of Tuttlingen's small firms are specialists in particular products, undertaking most processes in-house.

Despite intense local rivalry there is joint action between firms. The most significant examples are two 'associations' of firms. The mainly medium- and smallsized firms within these two groups maintain joint marketing and distribution functions. Moreover, each group has a shared research and development facility and well-recognized group brand names. This allows them to compete alongside the cluster's largest and most dominant firm. One of the two groups is now the cluster's second largest manufacturer of instruments and implants. Formal institutions, such as the chamber of commerce and the crafts chamber, also play an important role in the cluster. The cluster's leading training institution, the BBT (Berufliches Bildungszentrum Tuttlingen), is the only organization in Germany providing formal qualification in surgical instrument making.

Distribution patterns vary by product sub-sectors. In the highly concentrated endoscopes and implants sub-sectors, most firms are large and market directly to end-users. In contrast, there are three leading distribution channels in the instruments sub-sector.

- Direct sales to end-users, usually by large producers who supply from their own stock as well as sourcing instruments from small local producers.

- Sales to Tuttlingen-based traders by both larger and small producers.

- Sales to external traders who cover particular regional markets.

The latter is a traditional form of distribution for small Tuttlingen producers. External wholesalers and in particular large overseas buyers regularly visit the cluster 
to source products and some maintain buying offices in Tuttlingen. Tuttlingen-based actors dominate the domestic German market. In contrast, external buyers exercise the greatest influence in the US market.

\subsection{Inter-cluster and global value chain linkages}

In 1972, Tuttlingen's largest firm (Aesculap) became aware of Sialkot's abilities in instrument production. Realizing the competition from Sialkot, it established its own plant in Malaysia, gaining from low wages and tax advantages of Penang's free trade zone. This move towards global outsourcing was copied by the second largest instrument manufacturing group in Tuttlingen, which set up a joint venture unit in Sialkot in the early 1980s. Other Tuttlingen producers followed. In response to the problems of poor product quality, ties between Tuttlingen and Sialkot firms began with job processing. The former supplied the latter with the critical input, high quality stainless steel forgings. The Sialkot firms were responsible for the intermediate, and relatively labour intensive, tasks of grinding, filing and polishing. Semi-finished instruments were then returned to Tuttlingen for the final processes of further polishing, cleaning and packaging. In addition, there were significant flows of technical knowledge, machinery, and blueprints from Tuttlingen to Sialkot. Workers from Sialkot came to Tuttlingen for training, while technicians from Tuttlingen went to Sialkot to undertake quality inspections and advise on production practices. These connections are borne out in our field surveys. Of the 38 producers and traders questioned in the surgical instruments sector in Tuttlingen, ten directly sourced from OEM suppliers in Sialkot. Of these, eight claimed to be the main actors responsible in raising product quality of their Sialkot suppliers. Similarly, of the 42 producers interviewed in Sialkot, 15 stated that their main buyer was in Tuttlingen. Ten firms reported that their main Tuttlingen buyer was also engaged in production, and six claimed that their major source of new know-how came from their Tuttlingen buyer.

With improvement in metal forging in Sialkot during the 1980s and 1990s, job processing on pre-forged German instruments by the Sialkot cluster was replaced by OEM production. Exports of pre-forged job-processed instruments from Sialkot peaked at US\$ 3.40 million in 1993. By 2000, this had declined to US\$2.09 million. At the same time, there was a substantial increase in imports of instruments (both finished and job processed) from Sialkot to Tuttlingen, rising from US\$ 6.24 million in 1990 to US\$ 14.10 million in 1999 (Statistisches Landesamt Baden-Württemberg 2001). ${ }^{5,6}$

However, Sialkot is not the only supplier of instruments to the Tuttlingen cluster. In Malaysia, where Tuttlingen's largest producer increasingly uses its integrated plant to manufacture traditional hand-held instruments (especially forceps and scissors), a similar pattern is observed. Figure 1 refers to surgical instrument imports into the Tuttlingen cluster. Imports from Malaysia rose in line with those from Sialkot. Lately, however this has declined as Penang has matured into an OEM producer directly exporting to key regional markets. Similarly, Poland and Hungary developed in the 1990s as suppliers of finished instruments to Tuttlingen, although not on the same scale as Pakistan or Malaysia. Like Malaysia, production in Poland and Hungary is organized via chain ties with Tuttlingen. The largest Polish manufacturer was bought by Tuttlingen's leading producer. A number of other Tuttlingen manufacturers have similarly bought into Polish production units. In contrast, Hungary's former centralized and state-owned medical 


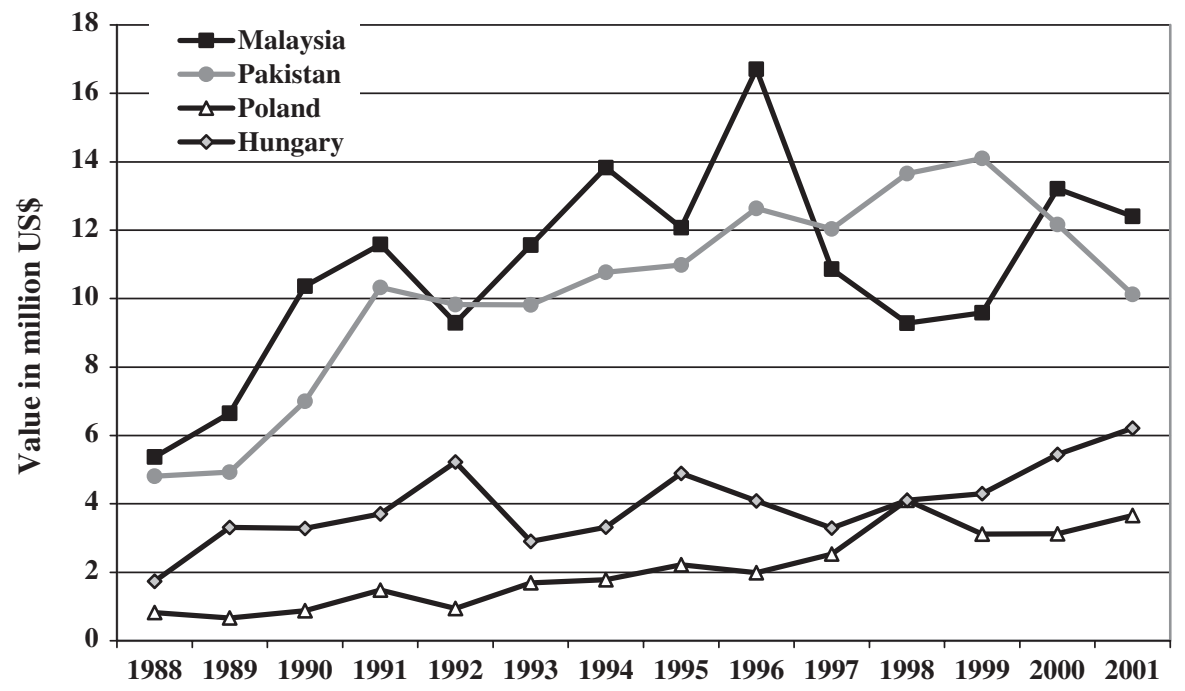

Figure 1. Surgical instrument imports from various locations to the Tuttlingen cluster- Baden-Württemberg.

Source: Statistisches Landesamt Baden-Württemberg (2001). (Converted to US\$ using IMF International Financial Statistics, 1999, 2001.)

engineering company was split into independent specialized units. The surgical instruments facility functionally upgraded by buying a Tuttlingen-based trader in order to more effectively channel its output to a global market.

In the last decade, there has also been a substantial rise in the numbers of specialist traders in Tuttlingen. Many of the small traders were former instrument producers who had been squeezed out of production due to cheap imports from Pakistan. Most significantly, three of the five largest traders in Tuttlingen are either wholly or partially foreign owned. One has minority and one majority Pakistani shareholding, while the third is wholly owned by the Hungarian manufacturer. These trends point to functional upgrading by both Sialkot and Hungary, acquiring the marketing and distribution functions that are concentrated in Tuttlingen, and providing market channels for Hungarian and Sialkot-made instruments. However, while the Hungarian owned trader only distributes the products of its parent company, the Pakistani-owned trader operates like other leading traders, directly sourcing from both Sialkot and Tuttlingen through arms-length ties with local suppliers.

In sum, there are three important distinctions to note in the nature of global value chain ties between Tuttlingen and Penang on the one hand, and Sialkot on the other. First, the range of producers and traders who have either direct or indirect ties to Sialkot is large. It includes large firms as well as small producers unable to compete against Sialkot. In contrast, ties with Malaysia are restricted to two of Tuttlingen's biggest firms. Second, Pakistani capital has established a trading foothold in Tuttlingen. Third, these patterns suggest very different forms of governance relations. Whereas ties between Tuttlingen and Penang are hierarchical, those between Sialkot producers and Tuttlingen buyers range from arms-length to quasi-hierarchical. 


\section{Upgrading in the Sialkot and Tuttlingen clusters}

The global surgical instruments industry faces three distinct challenges: reduce costs, adopt global standards, and develop new products. These call for distinct forms of process, product and functional upgrading, leading to a repositioning of firms, and clusters, within global value chains. As Humphrey and Schmitz (2002) argue, the potential for upgrading is influenced by governance within the local cluster and the global value chain. The subsequent discussion, structured around the three challenges, unravels patterns of upgrading in Sialkot and Tuttlingen and considers how this is associated to internal linkages within the cluster and external ties within the value chain.

\subsection{Costs}

Cost pressures are both supply and demand driven. The manufacture of traditional surgical instruments has seen a sustained entry of lower cost producers. The Tuttlingen cluster has faced competition from Sialkot, while intense local competition within Sialkot has lowered product prices. In addition, there are demands from buyers and end-users to reduce costs. This is, in part, an outcome of changing demographic and disease profiles. In addition, publicly-funded healthcare providers are under greater pressure to be cost-efficient (Knappe et al. 2000). This includes better control and maintenance of medical equipment inventories, more competitive sourcing of instruments, and a shifting of inventory costs and service functions down the chain to instrument suppliers. This requires surgical instrument suppliers to be more conscious of logistics, and the value-added of service, maintenance and financing activities.

There are various responses at the firm level to these pressures. In terms of process upgrading, firms in Tuttlingen introduced new productivity-enhancing machinery, including CNC machine tools, and adopted advanced production flow methods. Similarly, producers in Sialkot upgraded processes through new forging, heat treatment and die-making equipment. Process upgrading led to superior outcomes in Tuttlingen, with increasing turnovers for most sampled firms, and declining reject-rates in Sialkot, falling from an average of 7\% to under 3\% for sampled firms. Other responses to cost pressures in both clusters were to squeeze labour and increase local subcontracting.

A more significant response by Tuttlingen firms to costs pressures from below, as outlined above, is to outsource production to Sialkot and other low-cost locations. This has different implications for firms in Tuttlingen and those in the low-cost locations. As a number of mature product lines move from Tuttlingen to Sialkot and other locations, firms in Tuttlingen upgraded their products (with new product lines) and functions (such as trading and logistics). Thus, for example, Tuttlingen's largest producer now relies solely on its subsidiary plant in Malaysia for standard surgical instruments. Similarly, a number of Tuttlingen's former producers, especially small firms, have moved completely to trading while others have increased their trading activities. Most traders, either directly or indirectly, source instruments from OEM suppliers in Sialkot. These changes in Tuttlingen open up new opportunities for Sialkot producers to enter into product ranges that were formerly the preserve of Tuttlingen firms. There is evidence of Sialkot firms manufacturing more 
complex instruments, including tungsten-carbide (TC) tipped instruments used in vascular surgery, and laryngoscopes that require electrical and optical functions.

Cost-cutting pressures from buyers, linked with changes in hospital practices, have also led to forms of functional upgrading by instrument suppliers. Halder (2004) reports the growing practice of hospitals making joint purchases of instruments in order to reduce unit purchase prices, while some large European hospitals are transferring their inventory costs to their suppliers and increasingly leasing complex instruments. These developments are changing the functions undertaken by Tuttlingen's leading producers.

Tuttlingen's largest firm has developed service capabilities to track, sterilize, maintain and repair surgical instruments and apparatus that it supplies to individual hospitals. This required, inter alia, a joint venture arrangement with a foreign partner to develop the technical capacity to track instrument usage by its clients. Furthermore, through a merger with a large German (but not Tuttlingen-based) medical product supplier, the firm can now offer a full complement of instruments and medical products, and provide a 'full package service' that includes maintenance and servicing. By improving its logistics capabilities, it can supply complete operation kits to hospitals within Germany on a next day delivery basis. In addition, by providing leasing-based financing for more sophisticated, and least used, instruments it has enhanced its functional capabilities in response to costs pressures from buyers. Key informants suggest that leasing instruments and full operation kits is likely to grow in importance in the near future. In response to this, Tuttlingen's leading firm has transformed itself from being solely a producer of surgical instruments to a provider of a wide range of complex medical and surgical products and services.

\subsection{Quality assurance}

Since the early 1990s the medical products sector in most Western countries have had to comply with international quality assurance standards. ${ }^{7}$ These arise from public regulatory concerns in areas that impact on the health and safety of patients and medical professionals. In addition, new disease patterns, such as HIV-AIDS and non-variant CJD, have raised fears of contamination from used surgical instruments. These pressures have not only led to greater demand for disposable instruments, but also to improving accountability and traceability in manufacture to ensure that recognized quality procedures are adequately followed at each and every stage of production. Compliance with recognized global quality standards reduces the risk of buyers to failures by their suppliers. This has consequences for the nature of inter-firm linkages along the global value chain.

Adopting international quality standards requires detailed documentation of procedures, training of personnel, and constant monitoring of quality-related management practices through internal and external audits. Implementing standards can imply changes in production organization and management practices. It can also have implications for the relationships that producers have with suppliers. Furthermore, standards can have a differential impact. Small firms often lack the knowledge and resources needed for such process upgrading, and the costs of implementing standards and undertaking external audits can be prohibitive.

Compliance with international quality assurance standards in both clusters is extensive. ISO 9000, the leading global quality assurance standard, was widely 
adopted in Tuttlingen in the early 1990s. Local cluster institutions initially provided critical know-how on compliance and auditing. Meeting ISO 9000 norms is no longer seen as a challenge for Tuttlingen, although it remains an important concern for some of its low-waged suppliers.

In the mid-1990s, Sialkot's firms were excluded from the US for failing to meet US quality assurance standards, and were subsequently required to have ISO 9000 certification for the EU market. This forced local producers to improve quality management. The response was rapid. By 2000, over two-thirds of Sialkot's producers met the US as well as ISO 9000 standards (Nadvi 2004). This was achieved through local joint action and, to a lesser extent, ties with external buyers. In response to the initial challenge from the USA, the cluster's trade body 'bought-in' the technical know-how required to improve quality management procedures within the cluster. This helped local firms to later meet ISO 9000 standards. The adoption of ISO 9000 standards in the Sialkot cluster is widespread (now held by over 170 firms), and has come about with little or no support from local institutions or external buyers. Knowledge spillovers on quality management practices and the growing presence of specialist local consultants and auditors facilitated compliance. ${ }^{8}$ Yet, while most markets demand certification, the vast majority of sampled firms in Sialkot state that buyers are more concerned with price, quality, and delivery reliability. Moreover, widespread compliance has weakened rather than strengthened ties with buyers as stiff local competition amongst local producers has led to downward pressure on product prices.

The key messages from the challenge on quality assurance standards are that both clusters have responded positively. The impact, and the challenge, however, has been greater for Sialkot. Sialkot now delivers traditional instruments to the required global standards, although concerns remain as to whether quality standards actually bring about improvements in product quality.

\subsection{New product development}

The medical engineering sector is known for significant outlays on research and the rapid development of new products and techniques. ${ }^{9}$ In the last two decades, new research and technological developments have radically altered many surgical procedures. During the 1980s the development of endoscopes provided surgeons with a clear view of the abdominal cavity without the need for major trauma surgery. This allowed new operating techniques using specialized instruments which, with fibre-optic attachments, could be inserted into the body cavity through small incisions. This has come to be known as key-hole or minimally invasive surgery (MIS). MIS reduces hospital costs for patients, through quicker operations, often with local as opposed to general anesthetics, and shorter post-operative recovery time. During the 1990s, minimally invasive surgical procedures proliferated to include various types of obstetrics and gynaecological, abdominal, thoracic and head and neck surgery. Recently research has begun in developing multi-purpose MIS instruments that allow surgeons to undertake a mix of functions, thereby further reducing operating time. There have also been developments in the use of lasers and electro-medical scissors as cutting instruments, advances in micro-surgery and tele-surgery (that allow surgeons to conduct operations remotely using robotic instruments). Similarly, the marriage of electronics, computing and information technologies with surgery, such as the use of 
magnetic resonance scanners (MRS), has resulted in new types of advanced instruments, while enhancements in materials technologies have widened the range of artificial surgical implants, including hip and knee joints, heart valves and other body parts. New advances in bio-medical engineering include re-absorbable implants and micro-robotics.

These advances have significant implications for the Tuttlingen and Sialkot clusters. MIS instruments are produced using similar technologies to those required for mature instruments, but call for enhanced production skills. Large firms were at the forefront of their development in Tuttlingen. They began manufacturing MIS instruments in the mid-1980s. From the early 1990s, production of MIS instruments spread widely amongst small and medium-sized firms in the cluster. Of the 29 medium-sized instrument manufacturers (employing between 20 and 50 persons) in Tuttlingen today, 15 produce MIS instruments, while four are partly engaged in other fields of advanced medical engineering. In contrast, only a very few of the larger firms in Sialkot are in a position to produce the technically less complex MIS instruments.

Tuttlingen has also seen the rapid development of the endoscope sub-sector, with one of the leading global endoscope manufacturer located in the cluster. This firm began life in the 1960s as a classical surgical instrument producer. Another large, and technically advanced, endoscope producer in Tuttlingen is a leading OEM supplier to international buyers. Initially a producer of metal and glass syringes, this firm entered endoscope production by acquiring a firm engaged at the early stages of the development of endoscopic technologies.

The manufacture of endoscope, implants and apparatus now accounts for approximately half of total medical engineering employment in Tuttlingen. Tuttlingen's ten largest firms are all specialized in one or other of these new product lines. At the same time, many of the cluster's small firms have specialized in minimal invasive instruments, while some have begun to produce less complex surgical implants.

Such product upgrading in Tuttlingen is an outcome of the research and development activities of individual firms, and the technical benefits that have emerged through local cluster linkages and chain ties. The development of endoscopes and implants often required more technical as opposed to medical knowledge, such as computer-aided design, materials technology and advanced engineering techniques. In contrast, developing MIS instruments called for close contact with surgeons, the direct end-users, to get a better understanding of the functional needs of such instruments. ${ }^{10}$ Similarly, detailed and lengthy clinical trials and adequate testing of new implants is necessary before they can be licensed for use. This calls for close collaboration with hospitals and surgeons. While such trials are often standardized in nature, they require close dialogue and feedback between users (surgeons) and producers. Developing new surgical implants and endoscopes has also involved close ties with knowledge-intensive institutions and firms in other advanced technical sectors. In the development of endoscopes, for example, leading producers in Tuttlingen engaged with technical leaders in microscopic lighting, optical lenses and video camera technology. Thus, one large Tuttlingen-based endoscope producer enhanced its core competence by acquiring a specialist German optical lens manufacturer.

Developments in new product technologies appear to have had no impact on backward linkages with suppliers, such as in Sialkot, further down the value chains. Few of the leading producers of endoscopes and surgical implants have direct production ties with either the Sialkot cluster or with other low-waged production locations. 
In fact, one leading apparatus manufacturer which sourced instruments from Sialkot, sold its traditional instrument division 5 years ago as it no longer saw this as its area of core competence. Similarly, local cluster linkages have had a limited role in promoting upgrading around the new products in Tuttlingen. ${ }^{11}$ Instead, local cluster linkages tend to be geared to process and not product upgrading (Halder 2004). Once new products are developed, however, local linkages matter, especially for smaller firms who seek to copy or modify these products.

The findings from Tuttlingen show that competitive pressures are especially acute for small firms and for firms engaged in producing classical surgical instruments. Of the 21 small firms interviewed in Tuttlingen, 17 mainly produced classical instruments. Of the 14 medium to large firms, eight were primarily in the advanced products fields. Amongst small firms 13 expected turnover to decline in the next 5 years, while all medium to large firms predicted an increase in turnover.

As we have seen, Tuttlingen's large firms tend to concentrate on endoscopes and implants, leaving production of minimal invasive instruments to the medium and small firm sector. This differentiation points to the distinct knowledge requirements of these product groups, and to knowledge flows within the cluster. The Sialkot cluster, however, lacking either the technical capabilities to manufacture the new products or access end-users, has been unable to respond to this challenge. As the next section shows, this points to key differences in production and knowledge flows between the two clusters.

\section{Knowledge and production flows}

Knowledge and production systems are closely inter-related. This is a central theme in much of the innovation and learning literature (Lall 1992, Bell and Pavitt 1993, Storper 1993, Maskell and Malmberg 1999). Lundvall (1988), for example, stressed the learning potential of user-producer interactions. Stewart and Ghani (1991) observed how knowledge spillovers arising from firm agglomerations accelerated technical learning. Audretsch and Feldman (1996) took this further, arguing that innovation patterns in clusters are associated with product life cycles.

However, as Bell and Albu (1999) note, knowledge systems need to be distinguished from production systems. The latter refers to those processes that link labour, machinery, inputs and product designs that result in the manufacture and delivery of goods. In contrast, a knowledge system is dynamic. It consists of knowledge stocks (held within firms and individuals), knowledge flows (that take place within firms, between firms, within clusters, and along the value chain), and the 'organizational systems involved in generating and managing changes in the products, processes or organizations of production' (Bell and Albu 1999: 1723). Bell and Albu (1999) make a further distinction between the ability to apply and reproduce existing knowledge (what they refer to as 'knowledge-using capabilities'), and the ability to innovate, adapt and absorb new knowledge ('knowledge-changing capabilities').

As we show in the case of the global surgical instruments industry, distinguishing between knowledge and production systems helps to illustrate the differentiation within and between the two clusters. Knowledge and production flows, at the level of the firm, the cluster, and the chain, are first outlined for the mature products sector (traditional instruments) and then for the new products sector. 


\subsection{Knowledge and production flows in the mature instruments sector}

There are over 20000 different types of classical hand-held surgical instruments within what is viewed as the 'mature' products sector. Many of these were developed 50 or more years ago. While most have been refined, incrementally improved, or adapted for particular markets, the majority remain relatively standardized. Technical specifications are well known, and product blueprints are widely available. The manufacture of such instruments requires various metallurgical, chemical and metal-working skills. This includes knowledge of making appropriate steels, of making dies, and of forging, grinding, milling and filing of metals to high levels of precision. Some of these processes can be easily mechanized. Others rely heavily on skilled manual labour and incorporate the tacit knowledge of craft workers. Such knowledge is concentrated in the Tuttlingen and Sialkot clusters. It can also, as the experience from Penang indicates, be fostered by external actors in locations that have no earlier metalworking history. Thus, tacit knowledge in this sector can, as the Malaysian example suggests, be codified.

Mature instruments were originally designed through the collaborative efforts of surgeons (end-users) and instrument manufacturers. While the majority of mature instruments are now well-known products, amongst manufacturers and end-users, incremental innovations and improvements continue, requiring further user-producer interaction. Unlike Sialkot, Tuttlingen boasts long-standing historical and continuing links with leading surgeons.

What is apparent is the ways in which production flows in the manufacture of mature surgical instruments have transformed the industrial map of the global surgical instruments industry. While Tuttlingen continues to hold a quality advantage, as well as critical commercial benefits of reputable brand-names, the extent of production of such instruments has been declining within the cluster since the 1970s. Less than half the total employment in the cluster is currently engaged in producing mature products. Instead, many of Tuttlingen firms have turned to OEM suppliers in Sialkot, and to a lesser extent in other locations, to furnish it with such instruments. Tuttlingen firms provide distant suppliers with instrument designs and specifications, sometimes inputs and materials as well. There is also a clear flow of technical knowledge, aimed at process upgrading and involving machinery and advice on production organization, from Tuttlingen to Sialkot. A similar pattern is seen with Tuttlingen's largest firm and its subsidiary in Penang.

However, the flow of technical knowledge is costly, time consuming and unpredictable in its outcome. One concern is the very tacit nature of knowledge in surgical instrument production. This can be observed by a statement heard frequently during the fieldwork in both Tuttlingen and Sialkot: 'to be a good instrument manufacturer, you need at least ten years experience'. Despite the 3 years of formal training required in Tuttlingen to adopt the formal qualification of the profession, one can see that in both clusters knowledge is very much bound in with the levels of experience of individual workers. Yet, in Penang Tuttlingen's largest firm managed to offset the absence of a local knowledge base in metal-working by mechanizing key processes, and by investing in a 30-year period of constant knowledge transfer. A similar pattern of long-term knowledge flows is also seen between Tuttlingen and Sialkot. Thus, in both Sialkot and Penang, as mentioned earlier, the development has gone through different steps starting with job processing to OEM-production. Key informants state that Tuttlingen's largest producer managed to upgrade its Penang facility in a way 
that it can produce instruments at the required quality needed by advanced markets in Japan or North America. In contrast, Tuttlingen firms state that they still have to inspect, and often partly rework products, acquired on an OEM basis from Sialkot to make them acceptable for quality-driven markets. This difference may be an outcome of different governance and ownership patterns, leading to different degrees of investment in partners abroad.

This has implications for the Sialkot cluster. There is a pattern of differentiation. Firms that act as OEM suppliers in Sialkot are mainly large or medium-sized units. Small firms usually lack the requisite capability to produce the volume, the required quality and meet the delivery schedules imposed by buyers in Tuttlingen. Small firms are thus often restricted to lower quality, and lower value products that are distributed through production channels dominated by Pakistani traders abroad. In contrast, large and medium-sized firms have grown, in scale and in technical ability. The degree of job processing is declining as sales of finished and semi-finished instruments increases, and the range and quality of instruments produced by such firms in the cluster has expanded. Some of the technically more able firms have begun to specialize in more complex product lines, such as laryngoscopes. Moreover, along with the advances in product quality observed in Sialkot in recent years, Sialkoti firms have acquired a strong position in the expanding and high volume field of disposable instruments, a sub-sector where price competition is key.

For Sialkot's firms, operating in the cluster continues to generate important agglomeration economies. Some forms of institutional collaboration are also important, as was seen with the collective response to the challenge of meeting international quality standards. Yet, acquiring technical know-how and learning is increasingly determined by forward linkages with external actors. For many smaller firms, the flow of information within the cluster facilitates learning, as skilled workers and sub-contractors move from factory to factory. Nevertheless, the concentration of new knowledge in the hands of the larger producers suggests further differentiation within the cluster. Some large firms, including the largest firm in the Sialkot cluster, have sought to enhance their role as OEM suppliers to German and other foreign buyers, by developing their own brands. While original brand manufacture (OBM) remains limited, in the area of disposable instruments and in some of the more common, volume-based, clinical surgical instruments, OBM could offer a potential growth path for Sialkot's larger producers. It also implies that some of Sialkot's technically more competent producers may eventually enter the field of minimal invasive instruments. There is little to suggest, however, that firms in Sialkot could move to own design manufacture. Not only do the cluster's leading producers lack internal design capabilities, they have no direct links with end-users, either in Pakistan or abroad, and local technical institutions to support metallurgical and medical design developments are absent from the cluster.

Manufacturing MIS instruments requires the same set of skills, albeit at a higher level of precision, as classical instruments. There is, therefore, no reason to doubt that the production of such instruments or their components, initially through job processing and subsequently on an OEM-basis, could be transferred to Sialkot or by Tuttlingen's largest firm to its subsidiary in Penang.

As we have seen in the mature products sector, the knowledge system in Sialkot is tied to existing knowledge stocks of local artisans, and knowledge flows from external buyers, especially Tuttlingen-based producers (see figure 2 which captures knowledge and production flows between the two clusters regarding mature products). Such 


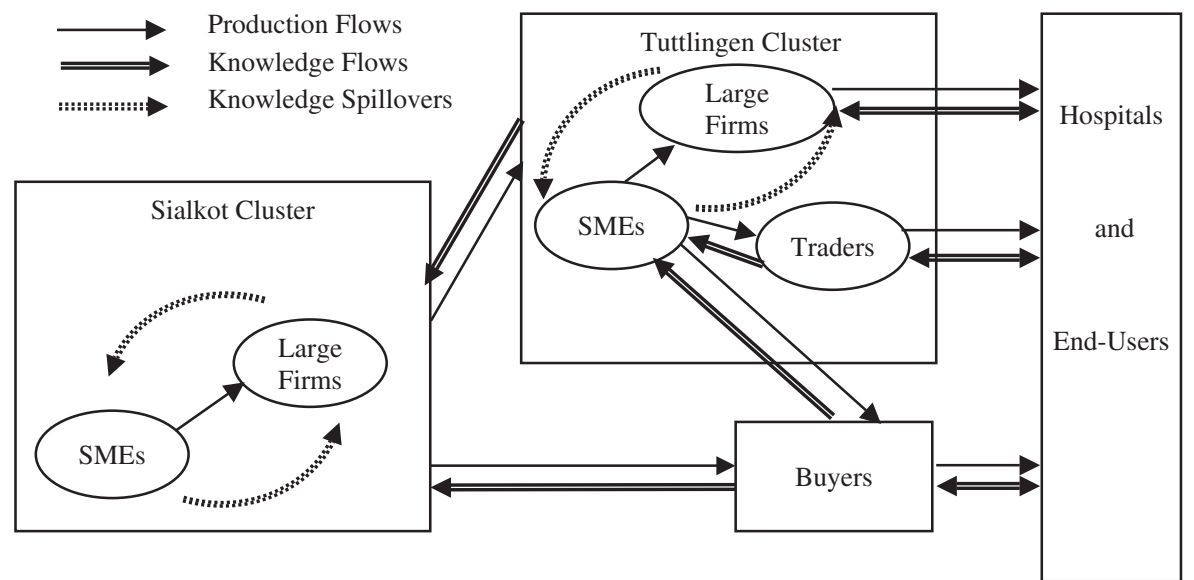

Figure 2. Knowledge and production ties between Sialkot and Tuttlingen in the mature products sector.

knowledge flows closely follow material and products flows, but the knowledge flows are uni-directional, from Tuttlingen to Sialkot, and are found in existing and well established channels that link Sialkot producers as OEM suppliers to Tuttlingen's firms. Such knowledge flows enhance what Bell and Albu (1999) term knowledgeusing capabilities. Acquiring know-how on adopting quality assurance procedures in production processes, and incorporating new technologies in manufacture, helped local producers in Sialkot to produce mature instruments more efficiently and meet quality assurance demands. It has not, however, led to the development of knowledgechanging abilities within the cluster. Nevertheless, the Sialkot cluster was able to upgrade within the existing knowledge system. Cluster gains mattered, especially in terms of knowledge spillovers. Yet, as Maskell and Malmberg (1999: 177) would put it, Sialkot's firms by imitating the skills that Tuttlingen had earlier acquired in the mature products sector, were in effect 'spending time and effort in learning yesterday's ways and skills'. This is not inconsequential. By raising its competence in production of mature instruments, Sialkot has put immense pressure on Tuttlingen. The response to this pressure has been uneven. Small firms in Tuttlingen have largely followed a 'reactive' strategy, moving towards trading with a decline in the production of (and employment in) mature instruments. Large Tuttlingen firms, however, developed a 'pro-active' response. They engaged suppliers in low-cost locations, and enhanced their knowledge-changing capabilities in order to move into the new products' sector and into new functions.

\subsection{Knowledge and production flows in the new products sector}

The new products sector includes the expanding range of minimal invasive instruments, endoscopes and surgical implants. Each of these product ranges requires awareness of metal working skills. However, these complex products link metalworking knowledge with complementary technologies. Thus, manufacturing endoscopes requires knowledge of optical lens, electrical, miniaturized image-enhancing lights, and video technologies. The manufacture of surgical implants calls for knowledge of materials technology, especially ceramics, plastics, metal alloys and titanium, and 
specialized surface treatments. It also relies heavily on sophisticated machine tools. Even the manufacture of minimal invasive instruments, which is primarily based on existing metal-based and metal-working knowledge, calls for enhanced skills in miniaturization, and for some instruments, awareness of ceramic and plastics technologies. The more advanced minimal invasive products often involve an interface with sophisticated electrical measurement apparatus that help surgeons to better visualize and control the instrument's functions.

Access to such knowledge requires skills that lie outside the Tuttlingen cluster. Thus, Tuttlingen's endoscope producers have either acquired, or entered into collaboration with, specialist firms in the field of optical lenses from outside the cluster. Some of the firms that were acquired were former suppliers. By bringing them in-house, endoscope manufacturers successfully internalized the new technologies. In the case of surgical implants, some firms strengthened backward links with specialist machine-tools suppliers, thereby raising their capabilities in the complex manufacturing procedures needed for sophisticated implants. In addition to links with knowledge-intensive firms from outside the Tuttlingen cluster, ties with end-users (surgeons and hospitals) and specialist public and private research institutes that lie outside the cluster have been important to the development of many of the new products.

Thus, for firms engaged in the manufacture of the technically advanced new products, ties external to the cluster gain importance. These either involve forward linkages within the value chain, such as the relationship with key surgeons in the production of MIS instruments, or backward linkages, as with machine tools producers in the implants sub-sector. They also underline the fact that as firms move from the mature products sector to new products, they also enter into new technical paradigms, involving new technical partners and competitors. ${ }^{12}$

This would suggest that in the development of the new products sector, local, cluster-based, knowledge ties are not of strategic importance. Yet, local linkages do matter for production flows and some knowledge flows. Take production flows. As many of the large firms move into the new products sectors, most continue to supply a range of instruments, including minimal invasive instruments and also classical instruments. To do so, they source from small OEM suppliers in Tuttlingen. Thus, for example, the cluster's largest firm has for some time relied on local OEM suppliers of specific instruments, although there are signs that this reliance is decreasing. Both groups of associated firms in Tuttlingen continue to turn to local OEM suppliers. The leading firms in the endoscope sector also rely on local suppliers to ensure that they can offer the full range of products under their name. Thus, cluster-based economies of scope, arising from local production linkages, remain important to large firms.

Similarly, the local knowledge base remains important. At a very basic level, the cluster offers new product manufacturers a pool of skilled and technically able labour. This skill base, reinforced through local institutions such as the training centre (the BBT), has both tacit knowledge and a thorough technical understanding of the industry. This makes it relatively easier, and quicker, for labour to absorb the new know-how and technologies required to develop and produce new products. Furthermore, the flow of technical knowledge within the cluster, through for example the movement of workers from firm to firm, raises the capabilities of many of the cluster's smaller producers. Thus, such firms acquire the capacity to eventually develop into OEM suppliers to the cluster's technical leaders. Moreover, skilled workers with the cluster's leading firms often leave to set up their own enterprises. 
These small spin-offs, while lacking the capability to develop new products, can copy and modify some of the new instruments at great speed. Such patterns of knowledge diffusion within the cluster stress the continuing importance of external economies in Tuttlingen's new products sector.

What is apparent is that the nature of product and knowledge flows reflects the differentiation within the Tuttlingen cluster. It is primarily the large and mediumsized firms that have entered the endoscopes, implants and surgical apparatus sectors. Large firms - regardless of their primary product focus - have their own research and development staff. Small firms tend to be restricted to the instruments sector although many now also produce minimal invasive instruments. A number of the small firms also act as OEM suppliers to large firms in the cluster, while some small firms have branched out into the area of specialized surgical implants. Most small firms, however, do not have the capacity to develop radical new products, and lack resources and research and development functions.

This disparity in the knowledge nexus of large and small firms becomes even more apparent in terms of the flow of specialist medical knowledge. Some large firms, such as Tuttlingen's lead firm, employ staff with medical and surgical training who are able to dialogue with end-users, read the appropriate technical journals and attend important surgical conferences and symposia. Thus, such firms are able to build more effective ties with end-users, are able to speak the technical language of surgeons, understand the nuances within the surgical field and have the power to convene surgeons. One key advantage of Tuttlingen's largest firm is that it has a medical conference facility on its Tuttlingen production site. This allows it to bring together leading surgeons from Germany and abroad, to listen to their deliberations, to engage them in discussions on product development, and, not least, to use the facility as a marketing tool.

So where does this leave the two clusters? As figure 3 shows, production and knowledge linkages arising from the new products, recognize cluster linkages within



Figure 3. Knowledge and production ties in the new products sector. 
Tuttlingen especially at the level of production, but also emphasize the importance of knowledge linkages outside Tuttlingen and further up the value chain. Whereas knowledge flows within Tuttlingen are essentially based on knowledge-using abilities (training of labour through the BBT, knowledge spillovers between local firms that accelerate the dissemination of manufacturing of new products within the cluster), knowledge flows that link cluster-based actors to firms and institutions outside Tuttlingen enhance knowledge-changing capabilities. These distinct types of knowledge flows also show how differentiation within Tuttlingen, as in Sialkot, is enhanced. Large firms have the knowledge necessary to make the qualitative leap to reach the technical frontiers in the development of many of the new product sub-sectors. As they do so, they come into technical contact, and competition, with a wider range of actors in the medical engineering field outside the cluster. Smaller firms, however, manage only incremental improvements. Some succeed in becoming OEM suppliers to large local producers while others carve out specialist niches in the new products sector, copying developments learnt from working in large firms. Numerous small firms continue to sell directly through local traders and foreign buyers. However, pressures from lower cost competitors force many of Tuttlingen's small firms to move to trading.

The distinct patterns of knowledge flows observed in the two clusters point to distinct cluster trajectories. These are closely associated with the distinct nature of product life cycles. Sialkot is engaged in a strategy of enhancing its market share in the mature products sector. This requires upgrading, but based on enhancing knowledgeusing abilities. In order to do this, it has relied on local cluster-based knowledge ties, and more importantly on external value-chain based knowledge ties. It is unable, however, to make the move to the new products sector. It lacks external channels through which the requisite knowledge to enter this sector could be acquired, and the knowledge base to absorb this knowledge even if it could access it. It is only through further upgrading in the mature products sector, and through greater investment in knowledge-using abilities that Sialkot will be in a position to develop the ability to enter what is currently seen as new products. Tuttlingen's trajectory has two dimensions to it, one based on its reputational advantage which allows it to act as the trading hub in the mature products sector, and the other in its enhanced abilities in adopting knowledge-changing capacities through ties with external actors. As Nooteboom (1999: 132) has argued there is a trade-off between effectively exploiting existing knowledge and the ability to invest in new knowledge. This is apparent in Tuttlingen, with small firms focusing on the former and large firms on the latter. Nevertheless, for the cluster as a whole, continued success rests on an agenda that incorporates both the development of new knowledge flows that leads to new products, as well as product flows, within the cluster and with lower cost locations, that enhance its ability to efficiently market mature products.

\section{Conclusion}

This paper began with the premise that while there is growing awareness of the importance of external linkages for the success of local industrial clusters, little is known of the ways in which distinct clusters relate to each other through global value chains. We raised three questions: first, how are clusters, especially from the North and the South, connected to each other? Second, how do they respond to 
common global challenges? Third, can production and knowledge flows within and between the clusters explain the distinct patterns of upgrading? In this concluding section we show how we have advanced the literature on industrial clusters and regional development, and consider the implications of our findings for the dynamic trajectories for clusters from the developed and the developing worlds.

The surgical instrument sector was used as a case study to explore connections and differences between the sector's two leading production clusters, one in Germany and the other in Pakistan. We used the frameworks of cluster and value chain analysis to investigate how upgrading, in response to common challenges, led to differing types of relationships between firms within each cluster, as well as between the two clusters. We also used distinctions developed in the recent literature on knowledge systems to understand how and why the two clusters occupy complementary but increasingly different roles in the global surgical instrument industry.

This study takes the literature forward in some significant ways. First, we provide comparative evidence on clusters engaged in the same sector from the developed and developing world, outlining their differences and similarities. Second, while Amin and Thrift (1992) point to clusters as nodes in global networks, we provide empirical evidence on how such nodes are linked. In differentiating between these nodes, we show how the developing country cluster concentrates on mature products whereas the developed country cluster is focused on the development and production of new products. While the two clusters used to compete with each other in many product lines, the relationship has become more complementary as the range of products made by each cluster diverges. More than that, the two clusters have developed close ties with each other. Improvements in product quality and production capabilities have shifted relations from job processing to original equipment manufacture. This helped firms in the Sialkot cluster to export independently to quality-driven global markets. Tuttlingen's producers played a key part in channelling technical advice, equipment and know-how to Sialkoti partners. At the same time, the price and quality competitiveness of the Sialkot cluster led to many Tuttlingen's producers moving away from production to trading activities, and to sourcing more heavily from Sialkot. Finally, there are signs that Pakistani capital has established an important presence within the Tuttlingen cluster as key traders. Since the Tuttlingen cluster marks the organizational hub of large parts of the production as well as of the distribution and the knowledge system in the sector, structural features have clear implications regarding upgrading and industrial policy. While the production capacity of the Sialkot cluster constantly evolves, partly due to knowledge flows from Tuttlingen, there is no indication that the division of labour between the clusters changes. This is an outcome of the quasi-hierarchical chains between firms in both clusters. Thus, as Humphrey and Schmitz (2000: 23) suggest, knowledge flows remain at the sphere of production and avoid functional upgrading. Hence, by showing the linkages between the clusters, we outline their competitive edge as well as their constraints.

Third, by focusing on the responses to common challenges faced by the two clusters, the paper provides a dynamic perspective on the nature of inter, intra, and extra-cluster linkages as well as on differentiation within and between the two clusters. The new challenges facing the surgical instruments sector come primarily from cost competition, advances in medical technology and surgical procedures, and international standards. To date, Sialkot has been particularly confronted by the latter of these challenges, whereas the first two challenges are more acutely felt in Tuttlingen. 
The response to these challenges has meant that the Sialkot and Tuttlingen clusters have become more sharply distinguished in terms of their main product lines.

The capacity of Tuttlingen's firms to undertake new product development is also linked to their wider regional location. As part of the regional economy of BadenWurttemberg, Tuttlingen's leading firms can draw on the capabilities of the other knowledge-intensive sectors. This includes machine tools producers (such as in nearby Gosheim), leading medical engineering firms and technical research institutions, advanced suppliers, and key research-oriented medical facilities. In contrast, the Sialkot cluster operates in a relative vacuum, with little or no technical links to the local light engineering and metal products sector, or the wider regional economy of the Punjab or even to Pakistan's major hospitals. Radical product developments often require links with national innovation systems - which exist in Germany but are lacking in Pakistan.

A further dimension of upgrading in Tuttlingen is functional in nature. Changes in the healthcare management systems are putting instrument suppliers under greater pressure to enhance the functions they offer their clients. It is not enough to supply instruments. Firms increasingly need to provide various services, from maintenance, repair and instrument sterilization to instrument control and tracking systems. Moreover, as hospitals push inventory costs down the supply chain, suppliers need to invest in holding a wider and diverse range of medical products, provide sophisticated logistics and chain management, and lease financing arrangements. This can be beyond the scope of all but the larger firms. The pattern of mergers in the medical products and medical engineering and pharmaceutical sectors underline the importance of economies of scale and scope. These arise from size and the range of products that the larger enterprise can offer. The growing concentration in the wider global medical engineering industry has serious implications for the ability of local firms and clusters to access knowledge flows, and upgrade. This would suggest that external linkages, especially ties with the larger medical products firms, may gain in significance over local linkages.

Thus, external and internal linkages both matter for understanding the competitive strengths and weaknesses of the two clusters, and they matter for the design of local and regional industrial policy. Such policy cannot just focus on the cluster as an entity in isolation, it needs to recognize the critical importance of linkages to the other cluster. That other cluster, which used to be a rival, can now become a strategic partner. Moreover, linkages external to both clusters, yet internal to the value chain, are likely to gain prominence in the future development of the two clusters, and in defining their competitiveness strategies.

\section{Acknowledgements}

The authors express their gratitude to the Volkswagen Stiftung for the funding for this study. They thank Sajid Kazmi for research assistance in Pakistan, and the various respondents interviewed in Germany, Pakistan and the UK for their insights. They also thank Hubert Schmitz, John Humphrey, Dirk Messner, Roberta Rabellotti, Judith Tendler, Gary Gereffi and Raphie Kaplinsky for suggestions on earlier drafts and are grateful to the anonymous referees for their extremely valuable comments. 


\section{Notes}

1. The fieldwork undertaken in Sialkot and Tuttlingen for this study is part of larger investigations in the two clusters by Nadvi (1999a,b, 2004) and Halder (2004, 2005), respectively. A total of 35 producers and 11 traders in Tuttlingen and 42 producers in Sialkot were interviewed in 2000 using semi-structured questionnaires and detailed firm case histories. Sampling was undertaken through a random selection from the membership lists of local trade associations and business guides as well as the purposive identification of key producers and traders identified through key informant interviews in both clusters. While the sample does not purport to be representative, it covers $7 \%$ of all producers and $13 \%$ of all traders in Tuttlingen and 12\% of all producers in Sialkot. The sample, while covering all size groups in both clusters, is especially biased in favour of large firms with one-third of all such firms being sampled in both clusters. The study also draws on a wider data base of interviews undertaken in the two clusters by the authors, including some 121 qualitative interviews in Tuttlingen and over 200 interviews carried out over several years, starting in 1993, in Sialkot.

2. This is estimated by taking the actual turnover of all firms with over 20 employees in the medical engineering sector in Tuttlingen - producing instruments, endoscopes, implants and apparatus. Output of small firms (with less than 20 employees) is estimated by taking the average labour productivity in small firms (obtained from the survey of small firms) and the total employment in the small firm sector. Our figures match those reported by key informants in Tuttlingen, and are in line with estimates in Nadvi (1999a). The data sources are the Statistisches Landesamt Baden-Württemberg 2000 (Vierteljährliche Produktionserhebung) and the Landesarbeitsamt Baden-Württemberg 2001 (on sectoral employment).

3. This draws on Nadvi (1999a,b, 2004).

4. This draws on Halder (2004, 2005).

5. The significance of the OEM status of Sialkoti firms and the subsidiary in Penang is also shown by the rise in the relative importance of exports of surgical instruments from Pakistan and Malaysia to countries other than the USA and Germany, see Halder (2005) for an analysis of recent export data.

6. While the data in figure 1 is at the country level, production of surgical instruments in each country is almost wholly concentrated in one location. For example, in Pakistan there is no manufacturing of instruments outside Sialkot, while Tuttlingen accounts for approximately $90 \%$ of firms, and employment, in the surgical instrument sub-sector in Baden-Württemberg.

7. The US Food and Drugs Administration (FDA) require all medical instruments suppliers in the USA to meet its good manufacturing practices (GMP) standards on quality assurance. Similarly, the EU (Directive 93/42/EEC) requires all producers of medical devices to meet international quality assurance standards such as ISO 9000 or EN 46000.

8. The speed with which ISO 9000 standards have been adopted in Sialkot has also raised concerns on the reliability of the certification process (Nadvi 2004).

9. According to Anderton and Schultz (1999: 16) research and development accounted for an average of $10 \%$ of the medical engineering sector's total sales revenues.

10. Close co-operation between manufacturers and surgeons has also been important in the development of other sub-sectors in medical equipment (Lawson and Lorenz 1999: 313).

11. However, an important new cluster initiative aimed at enhancing the ability of local firms in developing new MIS instruments is the Competence Centre. While it is too early to assess the impact of the centre on Tuttlingen, a point to note is that only medium and large firms have the technical skills to engage with the Centre (Halder 2004).

12. For example, an important competitor for Tuttlingen's endoscope producers is Olympus, a firm famous for cameras, which has diversified into the medical technologies sector and is a leading global producer of flexible, fibre-optic, endoscopes.

\section{References}

Amin, A. and Thrift, N. 1992 Neo-Marshallian nodes in global networks, International fournal of Urban and Regional Research, 16: 571-587.

Anderton, R. and Schultz, S. 1999 Explaining Export Success in the UK and Germany: A Case Study of the Medical Equipment Industry, Anglo-German Foundation for the study of Industrial Society, Layerthorpe (York: YPS).

Audretsch, D. B. and Feldman, M. P. 1996 Innovative clusters and the industry life cycle, Review of Industrial Organization, 11: 253-273.

Bair, J. and Gereffi, G. 2001 Local clusters in global chains: the causes and consequences of export dynamism in Torreon's blue jeans industry, World Development, 29: 1885-1903.

Bathelt, H., Malmberg, A. and Maskell, P. 2004 Clusters and knowledge: local buzz, global pipelines and the process of knowledge creation, Progress in Human Geography, 28: 31-56. 
Bathelt, H. and Taylor, M. 2004 Clusters, power and place: inequality and local growth in time-space, Geografiska Annaler, 84B (2): 93-109.

Bazan, L. and Navas-Aleman, L. 2004 The underground revolution in the Sinos Valley: a comparison of upgrading in global and national value chains, in Schmitz, H. (ed.), Local Enterprises in the Global Economy: Issues of Governance and Upgrading (Cheltenham: Edward Elgar).

Bell, M. and Albu, M. 1999 Knowledge systems and technological dynamism in industrial clusters in developing countries, World Development, 27: 1715-1734.

Bell, M. and Pavitt, K. 1993 Technological accumulation and industrial growth: contrasts between developed and developing countries, Industrial and Corporate Change, 2: 157-209.

Belussi, F. 1999 Policies for the development of knowledge-intensive local production systems, Cambridge Journal of Economies, 23: 729-747.

Best, M. 1990 The New Competition: Institutions of Industrial Restructuring (Cambridge: Polity Press).

Brusco, S. 1990 The idea of the industrial district: its genesis, in Pyke, F., Becattini, G. and Sengenberger, W. (eds), Industrial Districts and Inter-firm Cooperation in Italy (Geneva: ILO).

Garofoli, G. (ed.) 1992 Endogenous Development in Southern Europe (Aldershot: Avebury).

Garofoli, G. 1994 The industrial district of Lecco: innovation and transformation processes, Entrepreneurship E Regional Development, 6: 371-393.

Gereffi, G. 1994 The organization of buyer-driven global commodity chains: how U.S. retailers shape overseas production networks, in Gereffi, G. and Korzeniewicz, M. (eds), Commodity Chains and Global Capitalism (Westport, CT: Praeger).

Gereffi, G., Humphrey, J. and Sturgeon, T. 2002 The governance of global value chains: an analytic framework, Review of International Political Economy, 9: 436-464.

Gordon, I. R. and McCann, P. 2000 Industrial clusters: complexes, agglomerations and/or social networks? Urban Studies, 37: 513-532.

Halder, G. 2004 Local upgrading strategies in response to global challenges: the surgical instrument cluster of Tuttlingen, Germany, in Schmitz, H. (ed.), Local Enterprises in the Global Economy: Issues of Governance and Upgrading (Cheltenham: Edward Elgar).

Halder, G. 2005 Medizintechnik aus Tuttlingen und Sialkot: lokale producktion für den weltmarkt, Geographische Rundschau, 57 (2): 12-20.

Harrison, B. 1994 Lean and Mean: The Changing Landscape of Corporate Power in the Age of Flexibility (New York: Basic Books).

Humphrey, J. and Schmitz, H. 2000 Governance and upgrading: linking industrial cluster and global value chain research, IDS Working Paper 120 (Brighton: Institute of Development Studies).

Humphrey, J. and Schmitz, H. 2002 How does insertion in global value chains affect upgrading in industrial clusters? Regional Studies, 36: 1017-1027.

Knappe, E., Neubauer, G., Lindl, C., Seeger, T. and Sullivan, K. 2000 The value of medical devices in the German health care system (Trier: München).

Knorringa, P. 1996 Economics of Collaboration: Indian Shoemakers between Market and Hierarchy (London and New Delhi: Sage).

Krugman, P. 1991 Geography and Trade (Cambridge, MA: MIT Press).

Lagendijk, A. 2002 Beyond the regional life world against the global system world: towards a relationalscaler perspective on spatial-economic development, Geografiska Annaler, 84B: 77-92.

Lall, S. 1992 Technological capabilities and industrialisation, World Development, 20: 165-186.

Landesarbeitsamt Baden-Württemberg 2001 Betriebs- und Beschäftigtenstatistik (Stuttgart: Landesarbeitsamt Baden-Württemberg).

Lawson, C. and Lorenz, E. 1999 Collective learning, tacit knowledge and regional innovative capacity, Regional Studies, 33: 305-317.

Lundvall, B.-A. 1988 Innovation as an interactive process: from user-producer interaction to the national system of innovation, in Dosi, G., Freeman, G., Nelson, R., Silverberg, G. and Soete, L. (eds), Technical Change and Economic Theory (London: Pinter).

Malmberg, A. and Maskell, P. 2002 The elusive concept of localization economies: towards a knowledgebased theory of spatial clustering, Environment and Planning A, 34: 429-449.

Markusen, A. 1996 Sticky places in slippery space: a typology of industrial districts, Economic Geography, 72: 293-313.

Maskell, P. and Malmberg, A. 1999 Localised learning and industrial competitiveness, Cambridge Fournal of Economics, 23: 167-185.

Meyer-Stamer, J., Maggi, C. and Seibel, S. 2004 Upgrading in the tile industry of Italy, Spain and Brazil, in Schmitz, H. (ed.), Local Enterprises in the Global Economy: Issues of Governance and Upgrading (Cheltenham: Edward Elgar).

Nadvi, K. 1999a The cutting edge: collective efficiency and international competitiveness in Pakistan, Oxford Development Studies, 27 (1): 81-107.

Nadvi, K. 1999b Collective efficiency and collective failure: the response of the Sialkot surgical instrument cluster to global quality pressures, World Development, 27: 1605-1626.

Nadvi, K. 2004 Global standards and local responses, in Schmitz, H. (ed.), Local Enterprises in the Global Economy: Issues of Governance and Upgrading (Cheltenham: Edward Elgar). 
Nadvi, K. and Schmitz, H. (eds) 1999 Industrial clusters in developing countries, Special Issue of World Development, 27 (9): 1503-1734.

Nooteboom, B. 1999 Innovation, learning and industrial organization, Cambridge fournal of Economics, 23: $127-150$.

Porter, M. 1998 Clusters and the new economics of competition, Harvard Business Review, 76: 77-90.

Pyke, F. and Sengenberger, W. (eds) 1992 Industrial Districts and Local Economic Regeneration, International Institute of Labour Studies (Geneva: ILO).

Rabellotti, R. 1997 External Economies and Co-operation in Industrial Districts: A Comparison of Italy and Mexico (London: Macmillan).

Rabellotti, R. 2004 How globalisation affects Italian industrial districts: the case of Brenta, in Schmitz, H. (ed.), Local Enterprises in the Global Economy: Issues of Governance and Upgrading (Cheltenham: Edward Elgar).

Scott, A. 1994 Variations on the theme of agglomeration and growth: the gem and jewelry industry in Los Angeles and Bangkok, Geoforum, 25: 249-263.

Scott, A. 1996 Regional motors of the global economy, Futures, 28: 391-411.

Schmitz, H. 1995 Collective efficiency: growth path for small-scale industry, Fournal of Development Studies, 31: 529-566.

Schmitz, H. 1999 Global competition and local cooperation: success and failure in the Sinos Valley, Brazil, World Development, 27 (9): 529-566.

Schmitz, H. and Knorringa, P. 2000 Learning from global buyers, Fournal of Development Studies, 37: 177-205.

Schmitz, H. and Nadvi, K. 1999 Introduction, Special Issue of World Development, 27: 1503-1514.

Statistisches Landesamt Baden-Württemberg 2000 Vierteljährliche Produktionserhebung, Statistisches Landesamt, Stuttgart.

Statistisches Landesamt Baden-Württemberg 2001 Der Außenhandel, Statistisches Landesamt, Stuttgart.

Stewart, F. and Ghani, E. 1991 How significant are externalities for development?, World Development, 19: 569-594.

Storper, M. 1993 Regional worlds of production: learning and innovation in the technological districts of France, Italy and the USA, Regional Studies, 27: 433-455.

United Nations 2005 Statistics Division, Commodity Trade Statistics Database, http://unstats.un.org/unsd/ comtrade/

van Dijk, M. P. and Sverrisson, A. 2003 Enterprise clusters in developing countries: mechanisms of transition and stagnation, Entrepreneurship \& Regional Development, 15: 183-206.

Whitford, J. 2001 The decline of a model? Challenge and response in the Italian industrial districts, Economy and Society, 30 (1): 38-65. 